\title{
Components of respiratory resistance monitored in mechanically ventilated patients
}

\author{
B. Babik*, F. Peták", T. Asztalos", Z.I. Deák*, G. Bogáts`, Z. Hantos ${ }^{\#}$
}

Components of respiratory resistance monitored in mechanically ventilated patients. B. Babik, F. Peták, T. Asztalos, Z.I. Deák, G. Bogáts, Z. Hantos. (C)ERS Journals Ltd 2002.

ABSTRACT: The interrupter technique is commonly adopted to monitor respiratory resistance $(R r s, i n t)$ during mechanical ventilation; however, $R$ rs,int is often interpreted as an index of airway resistance (Raw).

This study compared the values of $R$ rs,int provided by a Siemens 940 Lung Mechanics Monitor with total respiratory impedance $\left(Z_{\mathrm{rs}}\right)$ parameters in 39 patients with normal spirometric parameters, who were undergoing elective coronary bypass surgery. $Z_{\mathrm{rs}}$ was determined at the airway opening with pseudorandom oscillations of $0.2-6 \mathrm{~Hz}$ at end inspiration. $R$ aw and tissue resistance $(R \mathrm{ti})$ were derived from the $Z_{\text {rs }}$ data by model fitting; $R$ ti and total resistance $(R \mathrm{rs}, \mathrm{osc}=R \mathrm{aw}+R \mathrm{ti})$ were calculated at the actual respirator frequencies. Lower airway resistance (Rawl) was estimated by measuring tracheal pressure.

Although good agreement was obtained between $R$ rs,osc and $R$ rs,int, with a ratio of $1.07 \pm 0.19$ (mean $\pm \mathrm{SD})$, they correlated poorly $\left(\mathrm{r}^{2}=0.36\right)$. $R \mathrm{ti}$ and the equipment component of $R$ aw accounted for most of $R$ rs,osc $(39.8 \pm 11.9$ and $43.0 \pm 6.9 \%$, respectively), whereas only a small portion belonged to $R$ awl $(17.2 \pm 6.3 \%)$.

It is concluded that respiratory resistance may become very insensitive to changes in lower airway resistance and therefore, inappropriate for following alterations in airway tone during mechanical ventilation, especially in patients with relatively normal respiratory mechanics, where the tissue and equipment resistances represent the vast majority of the total resistance.

Eur Respir J 2002; 20: 1538-1544
* Dept of Anaesthesiology and Intensive Therapy, ${ }^{\#}$ Dept of Medical Informatics and Engineering, and Division of Cardiac Surgery, University of Szeged, Szeged, Hungary.

Correspondence: Z. Hantos, Dept of Medical Informatics and Engineering, University of Szeged, Korányi fasor 9, H-6720 Szeged, Hungary.

Fax: 3662544566

E-mail: hantos@dmi.u-szeged.hu

Keywords: Airway resistance

forced oscillations

interrupter technique

respiratory monitoring

tissue resistance

Received: January 82002

Accepted after revision: July 192002

This study was supported by Ministry of Health grant No. 591/1996 06.
The accurate bedside monitoring of anaesthetised or critically ill patients involves a careful assessment of respiratory mechanics. Most of the recent commercially available ventilators are able to display the flow, pressure and volume changes throughout the respiratory cycles. From these signals, respiratory compliance $(C \mathrm{rs})$ and resistance $(R \mathrm{rs})$ are also calculated on-line.

$C_{r s}$ is a combined index characterising the elastic properties of the lung parenchyma and the chest wall. Many diseases, including emphysema and interstitial oedema [1], alter the elasticity of the lung parenchyma directly. Furthermore, $C_{\mathrm{rs}}$ is primarily affected by a loss in functional lung volume resulting from an increased closing capacity [2] leading to air trapping, or by abdominal distension [3].

$R$ rs is often considered to be a marker of airway resistance (Raw) [4-10] and is therefore, used to follow the respiratory strategy [8] and the effects of bronchoactive agents [5-7, 9, 10]. Nevertheless, it has been well established that a significant proportion of $R \mathrm{rs}$ can be attributed to energy loss in the respiratory tissues (tissue resistance $(R \mathrm{ti})$ ) [11-21]. Since the parameter $R$ rs is complex in nature, alterations in it may reflect pathological changes at different sites in the lungs. An increased $R$ rs may reflect an elevated Raw resulting from chronic obstructive pulmonary disease (COPD), an acute bronchospasm or mucus deposit in the airways. Alternatively, increases in $R \mathrm{ti}$ in diseases affecting the pulmonary parenchyma, such as adult respiratory distress syndrome $[4,5,22-24]$, COPD [20], cardiac failure [1] or congenital heart disease $[25,26]$, also elevate Rrs. Additionally, Rrs is often measured in such a way that it includes the resistance of the endotracheal tube (ETT), the connectors, the filters and the connecting tubing of the respirator $[7-9,22]$, i.e. the equipment resistance $(R e q)$.

Although it is evident that $R$ aw, $R$ ti and $R$ eq are all included in $R$ rs, their relative contributions have not been quantified. Accordingly, this study was performed in order to determine the airway, respiratory tissue and respiratory equipment components of $R_{\mathrm{rs}}$ displayed on a commonly used bedside ventilatory monitor. Since exact monitoring of the $R$ aw is crucial in following the response to bronchodilator therapy, the authors also aimed to verify whether $R$ rs calculated by the monitor during tidal ventilation adequately indicates changes in bronchial tone. 


\section{Methods}

\section{Subjects and preparations}

Thirty-nine patients (23 males, 16 female, 62 \pm 9 (mean \pm SD) yrs of age (range 40-78 yrs)) undergoing elective coronary bypass surgery were studied in the supine position before the surgical procedure. The protocol was approved by the Human Research Ethics Committee of Szeged University (Szeged, Hungary), and the patients gave their informed consent to the study. None of the patients had a history of COPD, and they did not have any respiratory problems at the time of the study. Indices of forced expiration were established 1 day before the surgery with a portable spirometer (Model PDD-301/s; Piston Ltd, Budapest, Hungary); the mean values of the predicted forced vital capacity and forced expiratory volume in one second of the group were $100 \pm 20$ and $93 \pm 19 \%$, respectively. The patients were premedicated with i.m. morphine $\left(0.1 \mathrm{mg} \cdot \mathrm{kg}^{-1}\right)$, midazolam $\left(0.07 \mathrm{mg} \cdot \mathrm{kg}^{-1}\right)$ and atropine $(0.5 \mathrm{mg}) 1 \mathrm{~h}$ before the operation. Anaesthesia was induced with $i . v$. fentanyl $\left(5-15 \mu \mathrm{g} \cdot \mathrm{kg}^{-1}\right)$ and midazolam $\left(0.05-0.07 \mathrm{mg} \cdot \mathrm{kg}^{-1}\right)$. Muscle paralysis was achieved with an i.v. bolus of pipecuronium bromide $\left(0.1 \mathrm{mg} \cdot \mathrm{kg}^{-1}\right)$. The trachea was intubated with a cuffed ETT 7,8 or $9 \mathrm{~mm}$ in internal diameter (ID), and the patients were ventilated with a Siemens 900C Servo Ventilator (Solna, Sweden) in the constant flow mode by adjusting the inspiratory/ expiratory ratio to $\sim 1: 3$. The ventilator frequency was set to $12-17 \mathrm{~min}^{-1}$, and a tidal volume $(V \mathrm{~T})$ of $8-12 \mathrm{~mL} \cdot \mathrm{kg}^{-1}$ and a positive end-expiratory pressure (PEEP) of $2 \mathrm{cmH}_{2} \mathrm{O}$ was applied. Maintenance doses of the anaesthetics and muscle relaxants were administered as needed.

\section{Oscillatory measurements}

The set-up used for the impedance measurements during short intervals of suspended mechanical ventilation is shown schematically in figure 1. Two collapsible latex tube segments (A and B) were clamped

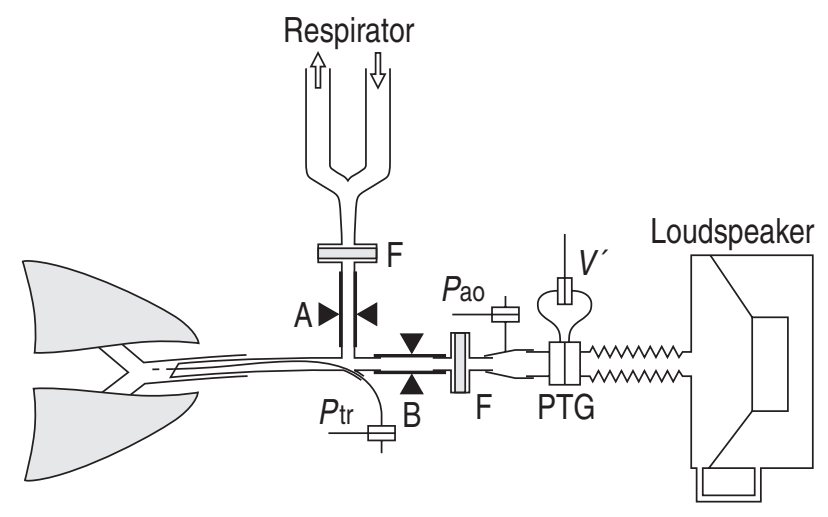

Fig. 1.-Schematics of the measurement set-up. $V^{\prime}$ : central airflow; $P$ ao: airway opening pressure; $P$ tr: tracheal pressure; $A$ and $\mathrm{B}$ : collapsible segments; PTG: pneumotachograph; F: antibacterial filter. alternately to switch the ETT from the respirator to the oscillatory device and back as follows. During mechanical ventilation, A was open and B closed. Before the first oscillatory measurement, the lungs were inflated to a pressure of $\sim 30 \mathrm{cmH}_{2} \mathrm{O}$ to standardise the volume history. Segment $\mathrm{B}$ was then opened for a few ventilatory cycles before data acquisition, in order to equilibrate the pressures in the lungs and the loudspeaker chambers. The respirator was stopped during the end-inspiratory plateau and segment A was clamped. In the resulting apnoeic period, smallamplitude $\left(<2 \mathrm{cmH}_{2} \mathrm{O}\right.$ peak-to-peak) pseudorandom pressure excitations were introduced into the trachea. The forcing signal contained 30 integer-multiple components of the $0.2-\mathrm{Hz}$ fundamental frequency, in the frequency range $0.2-6 \mathrm{~Hz}$. The component amplitudes were progressively enhanced with decreasing frequency so that a sufficient signal-to-noise ratio was provided over the whole frequency range. In order to decrease the involvement of nonlinear phenomena, the phases of the components were optimised so as to give the minimum pressure excursion at the airway opening [27].

Tracheal flow $\left(V^{\prime}\right)$ was measured with a $28-\mathrm{mm}$ ID screen pneumotachograph connected to a differential pressure transducer (ICS model 33NA002D; ICSensors, Milpitas, CA, USA). Airway opening pressure $(P$ ao $)$ was detected with an identical pressure transducer. To estimate the contribution of the impedance of the ETT and the antibacterial filter to the measurements, the tracheal pressure $(P \operatorname{tr})$ was measured with a third ICS sensor through a $1.5-\mathrm{mm}$ OD polyethylene catheter, the tip of which was furnished with several lateral holes and which was positioned $1.5-2 \mathrm{~cm}$ beyond the distal end of the ETT.

The recordings of oscillatory flow and pressures lasted for $15 \mathrm{~s}$. Four to five measurements were recorded, and $>2$-min intervals of ventilation were interposed between successive measurements. The input respiratory impedances $(Z \mathrm{rs})$ of the total and the lower respiratory system $(Z$ rsl $)$ were computed from the power spectra of $P$ ao and $V^{\prime}$ and $P \operatorname{tr}$ and $V^{\prime}$, respectively. The $Z$ rs and $Z$ rsl data were then ensemble-averaged separately and the data points at frequencies close to the cardiac frequency or its harmonics, and hence exhibiting large scatter, were discarded in both. The mean $Z$ rs data were fitted by a four-parameter model [13] containing a frequencyindependent Raw and inertance (Iaw) and a constantphase tissue compartment characterised by the coefficients of damping $(\mathrm{G})$ and elastance $(\mathrm{H})$ :

$$
Z_{\mathrm{rs}}(f)=R_{\mathrm{aw}}+\mathrm{j}(2 \pi \mathrm{f}) I_{\mathrm{aw}}+(\mathrm{G}-\mathrm{jH}) /(2 \pi f)^{\alpha}
$$

where $f$ is frequency, $\mathrm{j}$ is the imaginary unit and $\alpha=(2 / \mathrm{B}) \operatorname{tangent} \mathrm{t}^{-1}(\mathrm{H} / \mathrm{G})$. The $R \mathrm{ti}$ and the total respiratory resistance (Rrs,osc) at the frequency of mechanical ventilation $\left(f_{\mathrm{B}}\right)$ were respectively calculated as:

$$
R \mathrm{ti}\left(f_{\mathrm{B}}\right)=\left(2 \pi f_{\mathrm{B}}\right)^{\alpha}
$$

and

$$
R_{\mathrm{rs}, \mathrm{osc}}\left(f_{\mathrm{B}}\right)=R_{\mathrm{aw}}+R_{\mathrm{ti}}\left(f_{\mathrm{B}}\right)
$$


The Zrsl data were evaluated analogously to determine lower airway resistance (Rawl), lower airway inertance (Iawl), etc. pertinent to the lower respiratory system. Req was calculated as:

$$
R_{\text {eq }}=R_{\text {aw }}-R_{\text {aw } 1}
$$

The effective oscillatory compliance of the respiratory system at $f \mathrm{~B}$ was also computed, as:

$$
C_{\mathrm{rs}, \operatorname{osc}}\left(f_{\mathrm{B}}\right)=-1 /\left(\left(2 \pi f_{\mathrm{B}}\right) I_{\mathrm{aw}}-\mathrm{H} /\left(2 \pi f_{\mathrm{B}}\right)^{\alpha}\right)
$$

\section{Conventional mechanics}

The mechanical parameters were monitored by a Siemens Servo Computer Module (Type 990) attached to the respirator. The $R$ rs,int and $C$ rs,int values were read before and after the collection of impedance data, and their respective mean values were applied. According to the manual of the module, Rrs,int was calculated as the ratio of the pressure drop $(\mathrm{d} P)$ due to the interruption of inspiratory flow to the flow before interruption; $\mathrm{d} P$ was determined according to:

$$
\mathrm{d} P=P_{\max }-P_{\text {plateau }}
$$

where $P \max$ is the pre-interruption pressure and $P$ plateau was established at the end of the interruption interval $(10 \%$ of the ventilation period time). Crs,int was calculated as follows:

$$
C_{\mathrm{rs}, \text { int }}=V_{\mathrm{T}} /\left(P_{\text {plateau }}-\mathrm{PEEP}\right)
$$

\section{Statistical methods}

Scatters in the parameters were expressed as SD values. Paired t-tests and linear regression analysis were used to study the relationships between oscillatory and ventilatory mechanical parameters. BlandAltman analysis [28] was performed to determine the agreement between the respiratory resistances measured by the ventilatory monitor (Rrs,int) and by the forced oscillations $(R \mathrm{rs}, \mathrm{osc})$. A p-value $<0.05$ was considered to be significant.

\section{Results}

Figure 2 displays typical $Z$ rs and $Z$ rsl spectra obtained from a representative patient, with the best-fitting model curves, in terms of the real $(R \mathrm{rs})$ and imaginary part (reactance $(X \mathrm{rs}))$. The successive measurements yielded reproducible data at all frequencies except those coinciding with the heart frequency and its harmonics. Overall, the model was consistent with the measured data; only the slight increase in the measured $R \mathrm{rs}>\sim 4-5 \mathrm{~Hz}$, presumably a consequence of the frequency-dependent inertial distortion of the velocity profile and/or shunt effects in the central airways [29], led to systematic fitting errors. The decreases in both $R$ rs and $R$ rsl with frequency are attributed to the common tissue
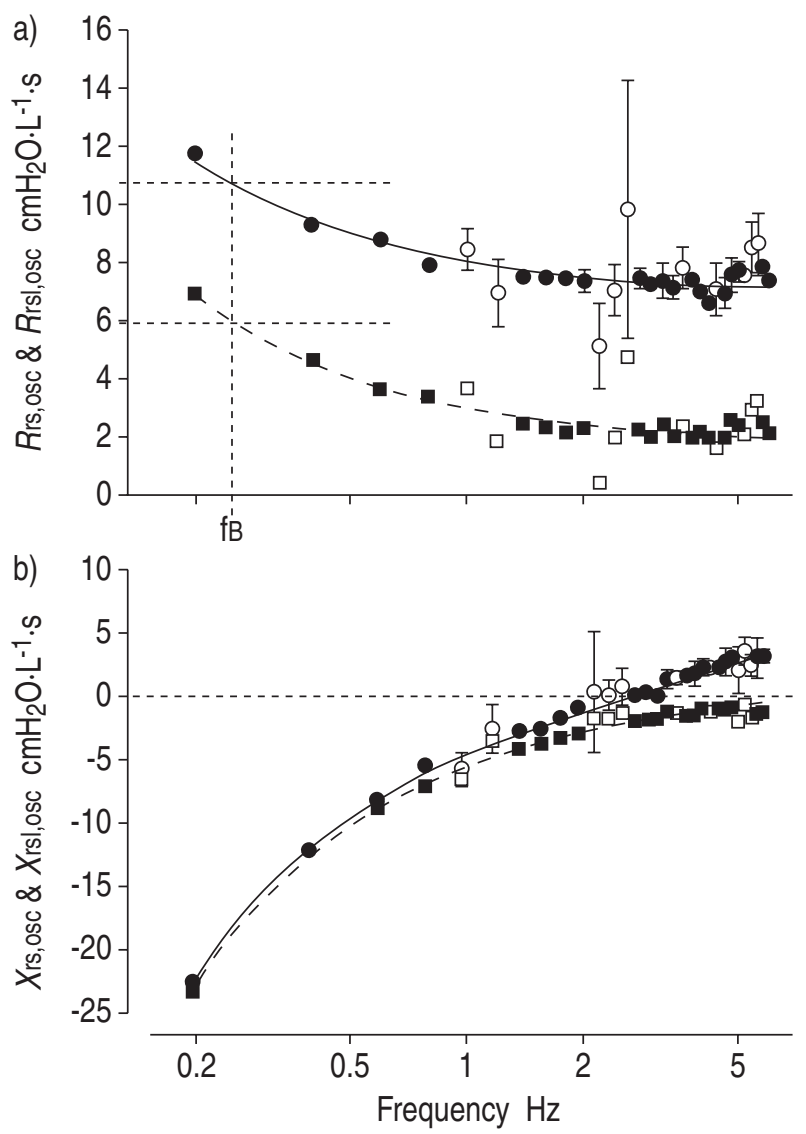

Fig. 2.-An example of respiratory input impedance data in one subject. Mean values from five successive measurements of a) total respiratory resistance $(R \mathrm{rs}, \mathrm{osc}:-)$ and lower respiratory resistance (Rrsl,osc: $\mathbf{0})$ and b) total respiratory reactance $\left(X_{\mathrm{rs}, \mathrm{osc}}:-\right)$, and lower respiratory reactance $(X$ rsl,osc: $\mathbf{\square})$ with the best-fitting model curves (continuous and dashed lines for the total and lower impedances, respectively). fB: frequency of ventilation. For clarity, the $\mathrm{SD}$ values are indicated for total impedance only. Open symbols indicate values corrupted by cardiac noise, exhibiting higher SD values and omitted from the model fitting. The difference between $R \mathrm{rs}, \mathrm{osc}(\mathrm{fB})$ and $R \mathrm{rsl}, \mathrm{osc}(\mathrm{fB})$ corresponds to the equipment resistance.

component, whereas the asymptotic levels of $R$ rs and $R$ rsl correspond to the airway components; the difference between them reflects the largely frequencyindependent contribution of the equipment resistance. The $X \mathrm{rs}$ and lower airway reactance $(X \mathrm{rsl})$ curves depart from each other with increasing frequency: the steeper increase in $X$ rs resulting in a resonant frequency at $\sim 3 \mathrm{~Hz}$ is a consequence of the substantial inertance of the equipment components.

The relationships between the interrupter and oscillatory resistance values are illustrated in figures 3 and 4 . The mean values of $R$ rs, int and $R \operatorname{rs}, o s c(f \mathrm{~B})$ were very similar $\left(10.1 \pm 1.9\right.$ and $10.6 \pm 1.9 \mathrm{cmH}_{2} \mathrm{O} \cdot \mathrm{L}^{-1} \cdot \mathrm{s}$, respectively). Although the correlation between $R$ rs,int and $R \mathrm{rs}, \operatorname{osc}(f \mathrm{~B})$ was statistically significant $(\mathrm{p}<0.005)$, the correlation coefficient was rather low, and Bland-Altman analysis revealed a lack of agreement between the two parameters, with limits of agreement of $3.1 \mathrm{cmH}_{2} \mathrm{O} \cdot \mathrm{L}^{-1} \cdot \mathrm{s}$ and $4.1 \mathrm{cmH}_{2} \mathrm{O} \cdot \mathrm{L}^{-1} \cdot \mathrm{s}$ (fig. 4). The values of $R$ aw $\left(5.97 \pm 1.19 \mathrm{cmH}_{2} \mathrm{O} \cdot \mathrm{L}^{-1} \cdot \mathrm{s}\right)$ and $R$ awl $\left(1.76 \pm 0.81 \mathrm{cmH}_{2} \mathrm{O} \cdot \mathrm{L}^{-1} \cdot \mathrm{s}\right)$ were much lower than those 

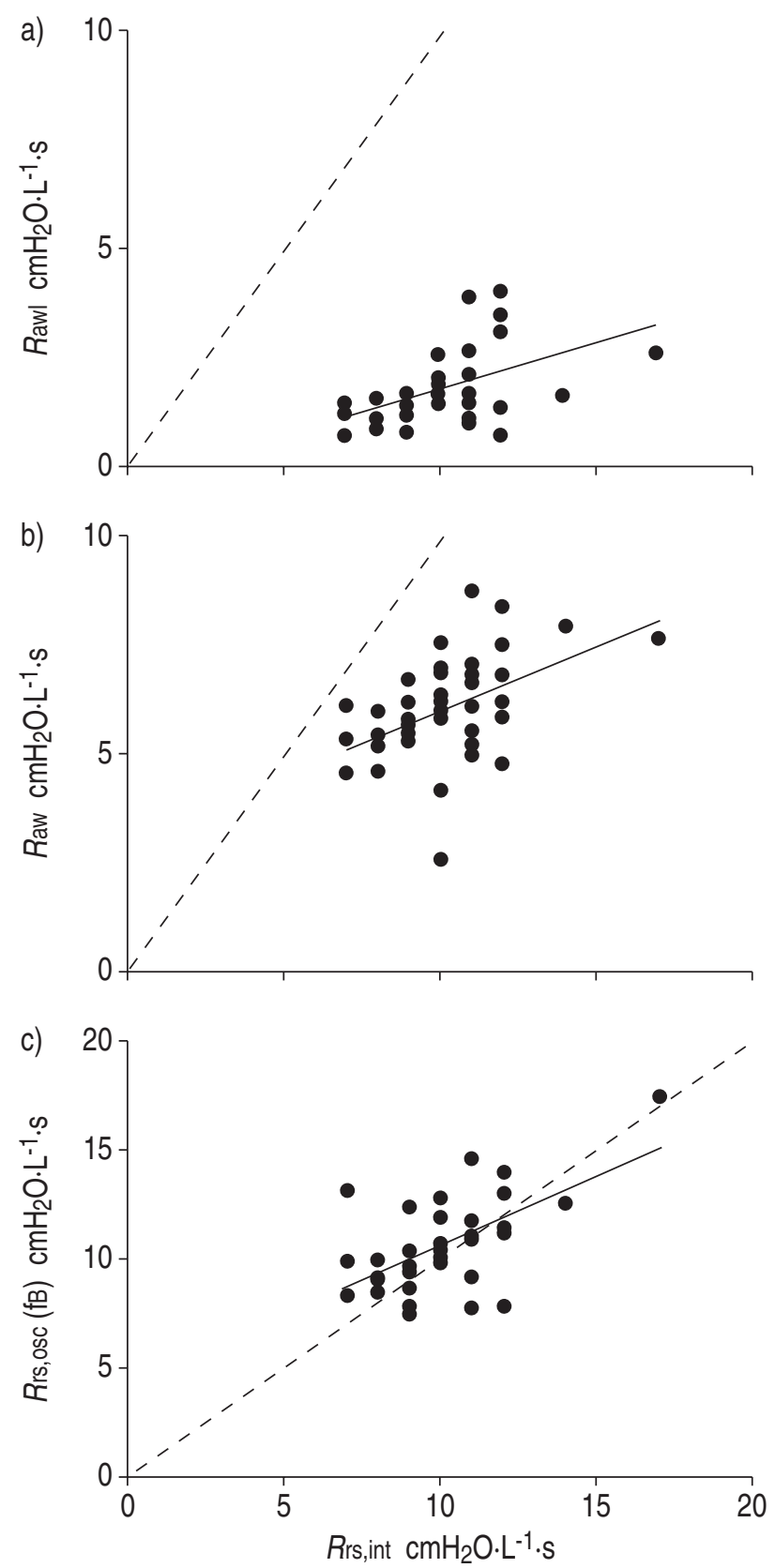

Fig. 3. - Relationship of interrupter resistance $(R \mathrm{rs}$,int) to lower airway resistance $\left(R \mathrm{awl}=-0.43+0.22 R \mathrm{rs}\right.$, int; $\left.\mathrm{r}^{2}=0.263\right)$, b) total airway resistance $\left(R \mathrm{aw}=3.0+0.30 R \mathrm{rs}, \mathrm{int} ; \mathrm{r}^{2}=0.240\right)$, and c) total oscillatory resistance at ventilation frequency $\left(R \mathrm{rs}, 0 \mathrm{osc}(\mathrm{fB})=4.1+0.6 R \mathrm{rs}\right.$, int; $\mathrm{r}^{2}=$ $0.365)$. Solid line: linear regression; dashed line: line of identity.

of $R \mathrm{rs}, \operatorname{osc}(f \mathrm{~B})$ and $R \mathrm{rs}$,int. Additionally, the correlations between the forced oscillatory airway resistances and $R$ rs,int were weak, although statistically significant ( $<<0.002$ for both). $R$ ti and $R$ eq accounted for most of $R$ rs,osc (39.8 $\pm 11.9 \%$ and $43.0 \pm 6.9 \%$, respectively), whereas only a much smaller portion of the total resistance could be attributed to the lower airways $(17.2 \pm 6.9 \%)$. There was a stronger correlation $(\mathrm{p}<$ 0.001 ) between the compliance estimates (fig. 5), with $C$ rs,int values being significantly higher $(\mathrm{p}<0.0001)$ than $C \mathrm{rs}, \mathrm{osc}(f \mathrm{~B})$ (a ratio of $1.4 \pm 0.19)$.

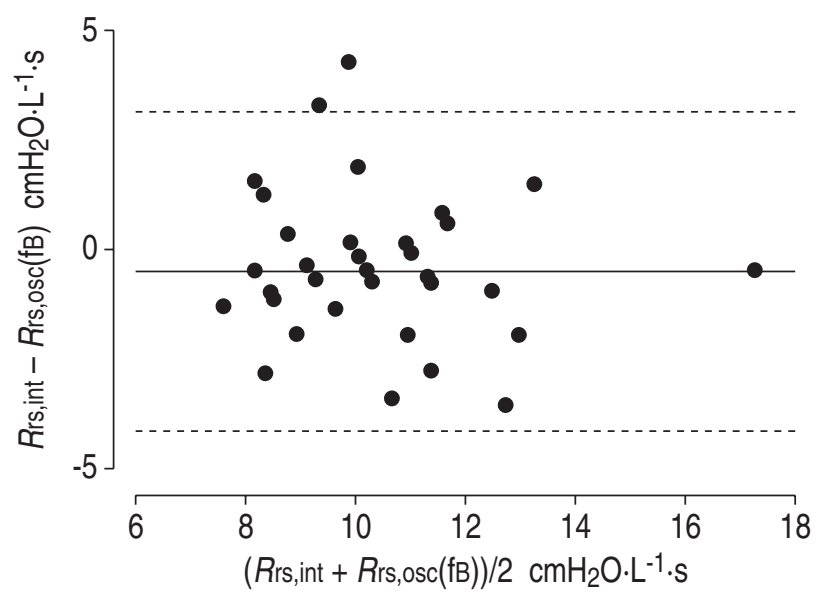

Fig. 4. - The differences between interrupter resistance $\left(R_{\mathrm{rs}, \text { int }}\right)$ and total oscillatory resistance at ventilation frequency $R \mathrm{rs}, \mathrm{osc}(\mathrm{fB})$ plotted against the mean of $R$ rs,int and $R$ rs,osc(fB) (Bland-Altman plot). The mean (solid line) \pm 2 SD levels (dashed lines: mean +2 $\mathrm{SD}=3.09$; mean-2 $\mathrm{SD}=-4.11$ ) indicate the limits of agreement.

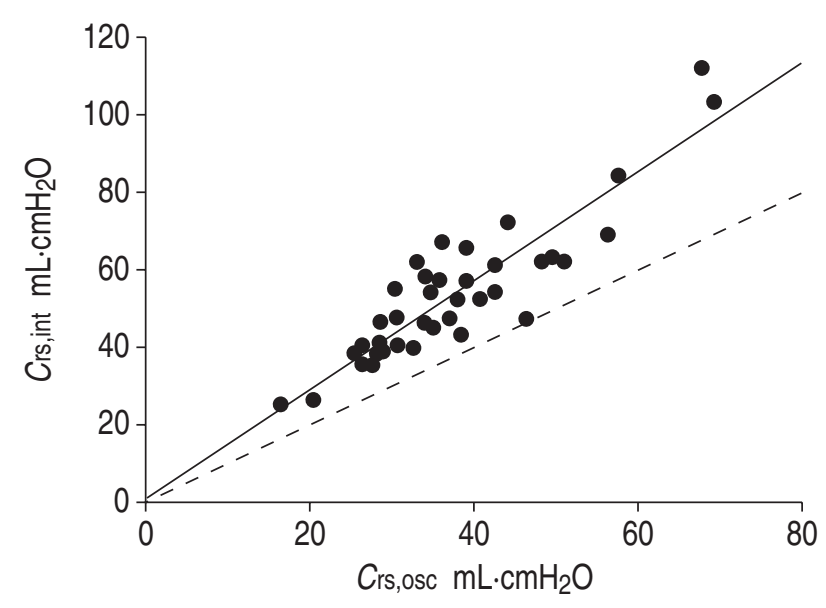

Fig. 5.-Relationship of dynamic respiratory compliance from tidal ventilation $\left(C_{\mathrm{rs}}\right.$,int $)$ to forced oscillatory compliance $(C \mathrm{rs}, \mathrm{osc})$ calculated at ventilation frequency $(\mathrm{fB})$. Solid line: linear regression; dashed line: line of identity. ${ }^{2}: 0.803 ; C_{\mathrm{rs}, \text { int }}=1.14+1.40 C_{\mathrm{rs} \text {, osc. }}$

\section{Discussion}

Previous investigations reporting total respiratory or pulmonary resistance often associated these parameters with the airways only [4-10]. Accordingly, the present study was designed to quantify the components of total respiratory resistance measured by a common bedside monitor. The results demonstrate that, during tidal ventilation of an intubated patient, a very high proportion of the dissipation in the respiratory system originates from the respiratory tissues and the flow resistance of the equipment. Rawl, the resistance component that can change because of an alteration in airway tone, comprised only a small fraction of the monitored resistance.

The low-frequency forced oscillation technique has been applied to partition total respiratory impedance into airway and tissue components in intubated 
patients free of cardiorespiratory disease [11], in normal subjects [15], COPD patients [20] and asthmatic patients receiving the optimal ventilatory waveform [21], and in healthy sedated infants [17, 18]. The interrupter technique has also been demonstrated to provide separate estimates for both airway resistance and tissue viscoelasticity [23, 24, 30-32]. If the flow in the central airway is interrupted rapidly, the tracheal pressure responds with a transient of two distinct phases, a sudden drop and a subsequent quasi-exponential decay. The initial change in pressure results from the cessation of flow in the Newtonian resistances, whereas the slow decay corresponds to the combined process of stress relaxation of the respiratory tissues and the interregional equilibration of inhomogeneous alveolar pressures. The interruption method is therefore a potential tool with which to separate the mechanical properties of the airways and the tissues in a similar manner as offered by the low-frequency oscillation technique $[12,20]$. Identification of these two phases, however, requires a fast interruption and a good-quality pressure recording for further analysis, both made as close to the airway opening as possible [30-32]. Since the long closure time and the proximal placement of the shutter in the respirator available for this study precluded the identification of the two phases, the current authors applied low-frequency oscillations for the separation of the airway and tissue components, and the intratracheal pressure recording to identify the instrumental component.

Although the $R$ rs,osc and $R$ rs,int values were obtained at the same end-inspiratory position, there are essential differences between these methods, and the relevance of the oscillatory ratio $R$ aw $/ R$ ti in $R \mathrm{rs}$,int is therefore not straightforward. $R$ ti was overestimated, with the oscillatory signal being smaller than the tidal deformation because of the negative amplitude dependence of tissue resistance [16]. However, $R$ aw was underestimated because of the use of oscillatory flows smaller than the inflation flow rate, which may have exceeded the limits of linearity (this is also true for Req, and especially its ETT component). These two opposing factors possibly cancelled each other out in the total resistance, which may explain the good agreement between the mean values of $R$ rs,int and $R \mathrm{rs}, \operatorname{osc}(f \mathrm{~B})$, but they must have modified the proportions of the tissue and airway components in $R$ rs,int from those predicted from the oscillatory data. Nevertheless, it is unlikely that these nonlinear effects could have led to a substantially higher airway/ tissue resistance ratio in $R$ rs,int than in $R \mathrm{rs}, \operatorname{osc}(f \mathrm{~B})$. It should also be noted that $R$ rs,int was calculated from a relatively short $(0.4-0.5 \mathrm{~s})$ end-inspiratory pause, which most likely resulted in overestimation of the values of $P$ plateau and hence $R$ rs,int that would have been obtained by more accurate interruption techniques with longer (3-5 s) end-inspiratory pauses [32].

Although the frequency-independent resistive component of $Z$ rs is fundamentally determined by the pulmonary system $[14,19]$, the chest wall has also been shown to have a frequency-independent resistive component $(R \mathrm{w})$ with a relative contribution reported to be $10-37 \%$ of the total Newtonian resistance [14, 19]. Since $Z$ rs spectra were used for the estimation of the resistive parameters of the airways in the present study, both $R$ aw and $R$ awl included $R$ w. Hence, the contribution of the intrathoracic airways to $R \mathrm{rs}$,osc and thus to $R$ rs,int is likely to be even smaller than the modest figure of $17.2 \%$.

Whereas the mean values of $R$ rs,int and $R \operatorname{rs}, \operatorname{osc}(f \mathrm{~B})$ were very similar $(R \mathrm{rs}, \mathrm{osc} / R \mathrm{rs}, \mathrm{int}=1.07 \pm 0.19)$ and their correlation was significant, Bland-Altman analysis revealed unacceptably wide limits of agreement between these parameters. Since the difference between the total resistance values obtained by the two methods did not display any systematic tendency (fig. 4), a random error was most probably responsible for this substantial discrepancy. Although the reasons for the inconsistency are not completely clear, temporal changes in the respiratory mechanics between the $R$ rs,int and $R$ rs,osc recordings, the poor resolution of the monitor displaying $R$ rs,int without showing decimals, or the noisy pressure signal limiting the accuracy of the estimation of the pressure drop following the occlusion might all have played a role.

The major finding of the present study is the very small contribution of the intrathoracic airways to the total resistance value displayed by the respiratory monitor. To estimate the specificity and sensitivity of Rrs,int in the detection of changes in airway calibre, the maximum possible change in Rawl that may remain hidden in the $R$ rs,int value monitored with poor resolution, as in the present case, was calculated. For a typical value of $R \mathrm{rs}$,int of $10 \mathrm{cmH}_{2} \mathrm{O} \cdot \mathrm{L}^{-1} \mathrm{~s}$, this round figure may represent any value between 9.51 and $10.50 \mathrm{cmH}_{2} \mathrm{O} \cdot \mathrm{L}^{-1} \mathrm{~s}$ (a range of $0.99 \mathrm{cmH} \mathrm{H}_{2} \mathrm{O} \cdot \mathrm{L}^{-1} \mathrm{~s}$ ). By assuming the mean contribution of Rawl to Rrs,int to be the same as that to Rrs,osc (i.e. $17 \%$ of $\left.10 \mathrm{cmH}_{2} \mathrm{O} \cdot \mathrm{L}^{-1} \mathrm{~s}\right)$, increases in Rawl not exceeding $0.99 \mathrm{cmH}_{2} \mathrm{O} \cdot \mathrm{L}^{-1} \mathrm{~s}$ may reach up to $67 \%$ and still remain undetectable in the monitored $R$ rs,int. It can therefore, be concluded that $R$ rs,int may become a rather insensitive measure of the airway properties, especially when the studied population, as in the present investigation, is free of airway diseases.

It is noteworthy that estimations of respiratory compliance were not subject to the problems associated with the measurement of resistance. A good correlation was found between the total respiratory compliances measured by forced oscillation and the respiratory monitor, though the latter were systematically greater (fig. 5). This difference can be explained by the principles of the two measurement methods. $C$ rs,osc was estimated from the oscillations applied around the end-inspiratory plateau and characterises the incremental elastic properties at that level. By contrast, $C$ rs,int represents an average compliance for the tidal excursion between endexpiration and end-inspiration at lower mean airway pressures $(P$ aw,mean). Both the lower $P$ aw,mean [18] and the larger excursions $[14,16]$ result in higher $C_{\text {rs, int }}$ than $C$ rs,osc, whereas, as noted above in connection with $R$ rs,int, the short end-inspiratory pause has an opposite effect on $C$ rs,int. Since the contributions of these factors depend on the subject and the respirator settings, they may explain both the systematic 
difference and the random scatter in the relationship of the compliance values.

To conclude, the results of the present study demonstrate that the total respiratory resistance displayed by a standard bedside respiratory monitor in intubated patients with normal respiratory mechanics is primarily determined by the viscous resistance of the respiratory tissues and the flow resistance of the devices of the ventilatory circuit, the contribution of the airway resistance being relatively small. The present data imply that the poor accuracy of the bedside monitor may even result in the changes following a severe increase (by more than two-thirds) in the lower airway resistance remaining undetected. In the event of heterogeneous narrowing of peripheral airways, elevations in Raw are accompanied by increases in $R$ ti $[13,16,19,21]$, which would augment the changes in Rrs,int; however, it is also possible that the alterations in $R$ aw and $R$ ti are independent [19]. Accordingly, both in routine clinical practice and under experimental conditions, much improved bedside monitoring techniques are advocated in order to follow the changes in airway tone and tissue mechanics during mechanical ventilation.

Besides a knowledge of the instrumental resistance component, a prerequisite for higher measurement sensitivity, it is of primary importance to choose methods with the ability to separate the airway and tissue components of total respiratory resistance, such as low-frequency forced oscillations $[11,17,20,21]$ and appropriately instrumented airway interruptions $[12,23,24,32]$.

Acknowledgements. The authors would like to thank L. Vígh and I. Kopasz for their excellent technical assistance and the staff of the Division of Cardiac Surgery for their cooperation.

\section{References}

1. Guntupalli KK. Acute pulmonary edema. Cardiol Clin 1984; 2: 183-200.

2. Estenne M, Gevenois PA, Kinnear W, Soudon P, Heilporn A, De Troyer A. Lung volume restriction in patients with chronic respiratory muscle weakness: the role of microatelectasis. Thorax 1993; 48: 698-701.

3. Gilroy RJ Jr, Lavietes MH, Loring SH, Mangura BT, Mead J. Respiratory mechanical effects of abdominal distension. J Appl Physiol 1985; 58: 1997-2003.

4. Wright PE, Bernard GR. The role of airflow resistance in patients with the adult respiratory distress syndrome. Am Rev Respir Dis 1989; 139: 1169-1174.

5. Wright PE, Carmichael LC, Bernard GR. Effect of bronchodilators on lung mechanics in the acute respiratory distress syndrome (ARDS). Chest 1994; 106: $1517-1523$.

6. Kil HK, Rooke GA, Ryan-Dykes MA, Bishop MJ. Effect of prophylactic bronchodilator treatment on lung resistance after tracheal intubation. Anesthesiology 1994; 81: 43-48.

7. Eames WO, Rooke GA, Wu RS, Bishop MJ. Comparison of the effects of etomidate, propofol, and thiopental on respiratory resistance after tracheal intubation. Anesthesiology 1996; 84: 1307-1311.

8. Berry A, Brimacombe J, Keller C, Verghese C. Pulmonary airway resistance with the endotracheal tube versus laryngeal mask airway in paralyzed anesthetized adult patients. Anesthesiology 1999; 90: 395-397.

9. Kim ES, Bishop MJ. Endotracheal intubation, but not laryngeal mask airway insertion, produces reversible bronchoconstriction. Anesthesiology 1999; 90: 391394.

10. Laude EA, Emery CJ, Suvarna SK, Morcos SK. The effect of antihistamine, endothelin antagonist and corticosteroid prophylaxis on contrast media induced bronchospasm. Br J Radiol 1999; 72: 1058-1063.

11. Navajas D, Farré R, Canet J, Rotger M, Sanchis J. Respiratory input impedance in anesthetized paralyzed patients. J Appl Physiol 1990; 69: 1372-1379.

12. Bates JHT, Daróczy B, Hantos Z. A comparison of interrupter and forced oscillations measurements of respiratory resistance in the dogs. $J$ Appl Physiol 1992; 72: $46-52$.

13. Hantos Z, Daróczy B, Suki B, Nagy S, Fredberg JJ. Input impedance and peripheral inhomogeneity of $\mathrm{dog}$ lungs. J Appl Physiol 1992; 72: 168-178.

14. Hantos Z, Adamicza Á, Govaerts E, Daróczy B. Mechanical impedances of lungs and chest wall in the cat. J Appl Physiol 1992; 73: 427-433.

15. Lutchen KR, Yang K, Kaczka DW, Suki B. Optimal ventilation waveforms for estimating low-frequency respiratory impedance. J Appl Physiol 1993; 75: 478488.

16. Barnas GM, Sprung J, Kahn R, Delaney PA, Agarwal $\mathrm{M}$. Lung tissue and airway impedances during pulmonary edema in normal range of breathing. $J$ Appl Physiol 1995; 78: 1889-1197.

17. Sly PD, Hayden MJ, Peták F, Hantos Z. Measurement of low-frequency respiratory impedance in infants. Am J Respir Crit Care Med 1996; 154: 161-166.

18. Peták F, Hayden MJ, Hantos Z, Sly PD. Volume dependence of respiratory impedance in infants. $\mathrm{Am}$ J Respir Crit Care Med 1997; 156: 1172-1177.

19. Suki B, Peták F, Adamicza Á, Daróczy B, Lutchen KR, Hantos Z. Airway and tissue constrictions are greater in closed than in open-chest conditions. Respir Physiol 1997; 108: 129-141.

20. Farré R, Ferrer M, Rotger M, Torres A, Navajas D. Respiratory mechanics in ventilated COPD patients: forced oscillation versus occlusion techniques. Eur Respir J 1998; 12: 170-176.

21. Kaczka DW, Ingenito EP, Israel E, Lutchen KR. Airway and lung tissue mechanics in asthma. Effects of albuterol. Am J Respir Crit Care Med 1999; 159: 169-178.

22. Broseghini C, Brandolese R, Poggi R, Bernasconi M, Manzin E, Rossi A. Respiratory resistance and intrinsic positive end-expiratory pressure (PEEPi) in patients with the adult respiratory distress syndrome (ARDS). Eur Respir $J$ 1988; 1: 726-731.

23. Pelosi P, Cereda M, Foti G, Giacomini M, Pesenti A. Alterations of lung and chest wall mechanics in patients with acute lung injury: effects of positive end-expiratory pressure. Am J Respir Crit Care Med 1995; 152: 531-537.

24. Morina P, Herrera M, Venegas J, Mora D, Rodriguez M, Pino E. Effects of nebulized salbutamol on respiratory mechanics in adult respiratory distress syndrome. Intensive Care Med 1997; 23: 58-64. 
25. Freezer NJ, Lanteri CJ, Sly PD. Effect of pulmonary blood flow on measurements of respiratory mechanics using the interrupter technique. J Appl Physiol 1993; 74: 1083-108.

26. Lanteri CJ, Kano S, Duncan AW, Sly PD. Changes in respiratory mechanics in children undergoing cardiopulmonary bypass. Am J Respir Crit Care Med 1995; 152: 1893-900.

27. Daróczy B, Hantos Z. Generation of optimum pseudorandom signals for respiratory impedance measurements. Int J Biomed Comput 1990; 25: 21-31.

28. Bland JM, Altman DG. Statistical methods for assessing agreement between two methods of clinical measurement. Lancet 1986; 1: 307-310.
29. Finucane KE, Dawson SV, Phelan PD, Mead J. Resistance of intrathoracic airways of healthy subjects during periodic flow. J Appl Physiol 1975; 38: 517-530.

30. Bates JHT, Rossi A, Milic-Emili J. Analysis of the behavior of the respiratory system with constant inspiratory flow. J Appl Physiol 1985; 58: 1840-1848.

31. Sly PD, Bates JH, Milic-Emili J. Measurement of respiratory mechanics using the Siemens Servo Ventilator 900C. Pediatr Pulmonol 1987; 3: 400-405.

32. D'Angelo E, Robatto FM, Calderini E, et al. Pulmonary and chest wall mechanics in anesthetized paralyzed humans. J Appl Physiol 1991; 70: 26022610 . 